Agric. Biol. Chem., 42 (10), $1907 \sim 1910,1978$

\title{
Structure of a New Phenolic Glycoside, Chesnatin, from Chestnut Galls ${ }^{\dagger}$
}

\author{
Tetsuo OzaWa, Nobuo Arai* and Yoshinori Takino \\ Institute of Applied Biochemistry, The University of Tsukuba, \\ Sakura-mura, Nïhari-gun, Ibaraki-ken 300-31
}

Received June 6, 1978

\begin{abstract}
The chemical structure of the tannic substance chesnatin isolated from chestnut galls was presented as I on the basis of spectral data and its enzymatic hydrolysis products, although it remained to be established which carboxyl group of dehydrodigallic acid was esterified. Chesnatin was found in nature for the first time.
\end{abstract}

In the previous paper, ${ }^{1)}$ we reported the isolation and some properties of the tannic substances, tentatively named MP-3 and MP-4, contained in chestnut galls. They were recognized to be closely related compounds consisted of the same components. Recently, the structure of MP-3, which was named chestanin, was elucidated. ${ }^{2}$ The present paper deals with structure elucidation of another minor compound MP-4. On this occasion, we propose to give proper name "chesnatin" to this compound.

Chesnatin (I) is colorless needles which has no distinct melting point. As described in the previous paper, ${ }^{1 /}$ the enzymatic hydrolysis of chesnatin with crude tannase preparation gave 3,4,5-trihydroxybenzyl alcohol, dehydrodigallic acid and D-glucose, which were confirmed by paper chromatography. Since chesnatin gave the same constituents as chestanin, the elucidation of the structural difference between these two compounds is the present problem.

Acetylation of chesnatin with acetic anhydride and pyridine afforded a powdery peracetate (II), mp $128 \sim 130^{\circ} \mathrm{C}, \mathrm{C}_{49} \mathrm{H}_{48} \mathrm{O}_{29}$. The PMR spectrum of II showed four singlets at $\delta 2.01(3 \mathrm{H}), 2.04(3 \mathrm{H}), 2.08(3 \mathrm{H})$ and 2.13 (3H) $\mathrm{ppm}$ due to sugar acetyl groups. The singlets $(21 \mathrm{H})$ at $\delta 2.27,2.29$, and $2.31 \mathrm{ppm}$ were assigned to seven aromatic acetyl groups.

i Biochemical Studies on Chestnut Galls. Part VI. See reference 2) for Part $V$.

* Present address: Toyo Soda Manufacturing Co., Ltd., 4560 Tonda, Shinnanyo-shi, Yamaguchi-ken 746.

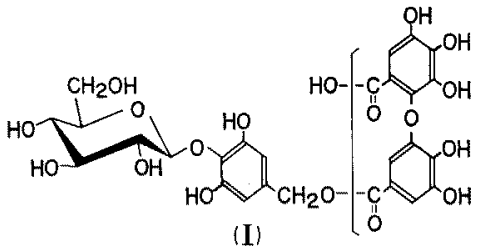

The sugar protons were detected at $\delta 3.65$ $(1 \mathrm{H}, \mathrm{m}), 3.91(1 \mathrm{H}, \mathrm{d}, J=12 \mathrm{~Hz}), 4.37(1 \mathrm{H}, \mathrm{dd}$, $J=12$ and $4 \mathrm{~Hz}), 4.90(1 \mathrm{H}, \mathrm{m})$, and $5.12 \sim 5.21$ $(3 \mathrm{H}, \mathrm{m}) \mathrm{ppm}$. The singlet at $\delta 6.89(2 \mathrm{H}) \mathrm{ppm}$ was ascribed to two aromatic protons of hydroxybenzyl alcohol moiety. Two doublets at $\delta 7.07(1 \mathrm{H}, J=2 \mathrm{~Hz})$ and $7.62(1 \mathrm{H}, J=2 \mathrm{~Hz})$ ppm, and a singlet at $\delta 7.86(1 \mathrm{H}) \mathrm{ppm}$ were assigned to aromatic protons due to dehydrodigallic acid moiety. The methylene protons belonging to hydroxybenzyl alcohol moiety were observed in the multiplet at $\delta 5.12 \sim 5.21$ $(2 \mathrm{H}, \mathrm{m}) \mathrm{ppm}$. These results suggested that chesnatin consisted of each one molecule of 3,4,5-trihydroxybenzyl alcohol, dehydrodigallic acid and glucose, different from the case of chestanin. ${ }^{21}$ Quantitative acid hydrolysis of chesnatin supported this presumption by giving

Table I. Quantitative Analysis of the Constituents of Chesnatin

\begin{tabular}{|c|c|c|c|}
\hline $\begin{array}{l}\text { Sample } \\
(\mathrm{mg})\end{array}$ & & $\underset{(\mathrm{mg})}{\mathrm{DDGA}^{a}} \mathrm{G}^{b}$ & $\begin{array}{l}\text { Molar ratio } \\
\text { DDGA : G }\end{array}$ \\
\hline \multirow[t]{2}{*}{21.424} & Found & 11.539 & $1.07: 1$ \\
\hline & Calcd. & 11.350 & $1: 1$ \\
\hline
\end{tabular}

a Dehydrodigallic acid.

b Glucose. 


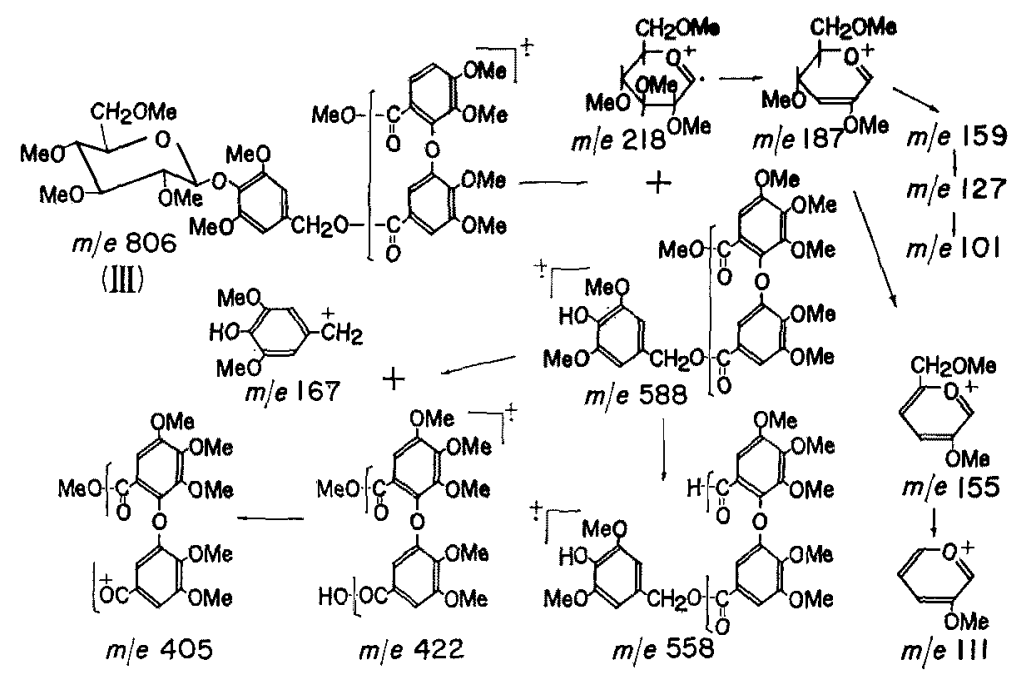

SCHEME 1.

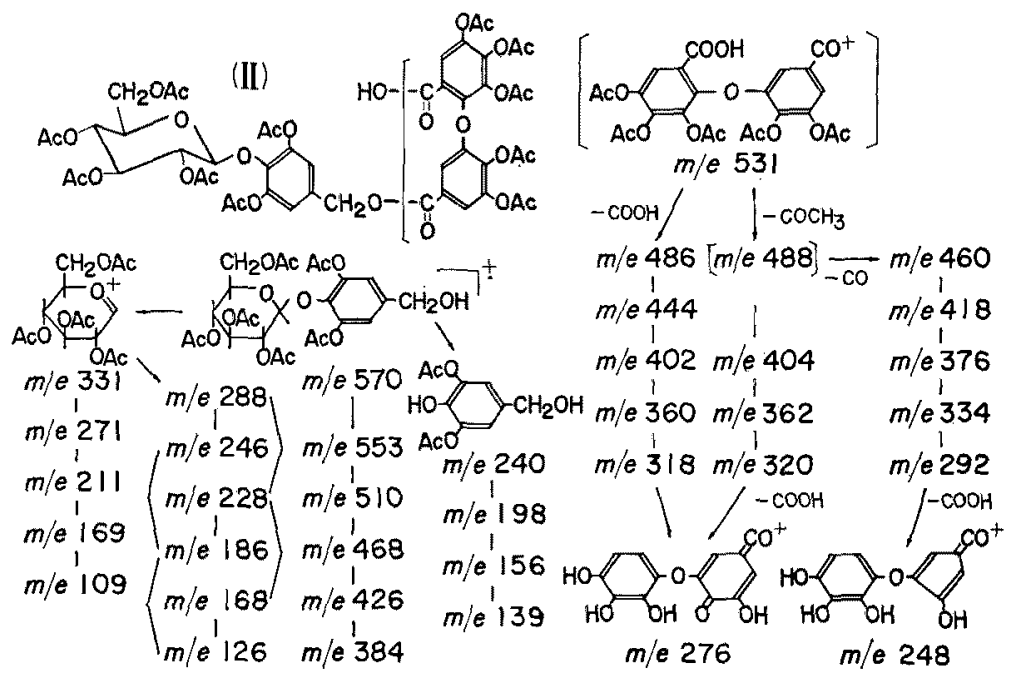

SCHEME 2.

a molar ratio of glucose to dehydrodigallic acid 1: 1 (Table I).

Mass spectrometry of permethyl (III) and peracetyl (II) derivatives gave suggestive information for the linking positions and the sequence of each constituent (Schemes 1 and 2). The mass spectrum of III showed the characteristic fragmentation peaks at $m / e 588,422$, 218 , and 167 with a very weak molecular ion peak at $m / e$ 806. The peak at $m / e 422$ and 167 can be assigned to pentamethyl dehydrodigallic acid monomethyl ester and 3,5-dimethoxy-4hydroxyphenyl-methine ion, respectively, due to secondary fragmentation of the aglycone. The presence of the peaks at $m / e 588$ and 422 suggests that one of carboxyl groups in the dehydrodigallic acid moiety is free. The peak at $m / e 218$ corresponds to tetramethylglucose oxonium ion characteristic of permethyl phenyl glucoside. ${ }^{3)} \quad$ The mass spectrum of $\mathbf{I}$ was very similar to that of peracetyl chestanin." It showed no molecular ion and the peak corresponding to the aglycone, however, it gave a series of the fragmentation peaks derived from each constituent. The weak peak at $m / e 570$ consists of glucose and trihydroxybenzyl alco- 
hol moiety, and the peak at $m / e 240$ corresponds to trihydroxybenzyl alcohol moiety. The prominent peak at $m / e 276$ is attributable to the loss of one carboxyl and five ketenes from pentaacetyl dehydrodigallic acid moiety. Another two series of peaks from $m / e 404$ to $m / e 276$ and $m / e 460$ to $m / e 248$ are also attributable to the fragments derived from the same moiety. Since all hydroxyl groups in the dehydrodigallic acid moiety are judged to be acetylated, it should combine with the other constituents through an ester linkage. Further, in the secondary fragmentation pathway of pentaacetyl dehydrodigallic acid moiety, it was observed that the fragmentation started from elimination of carboxyl group gave a noticeable intensity compared to that of peracetyl chestanin. As the result, it was presumed that this fragmentation occurred easily when a free carboxyl group was attached to the benzene ring having three acetyl groups in pentaacetyl dehydrodigallic acid moiety. The peak at $m / e 331$ is assigned to tetraacetylglucose oxonium ion which is familiar to the peracetylglucoside having no substituent except at $\mathrm{C}-1$ of glucose.

In addition, ${ }^{13} \mathrm{C}-\mathrm{NMR}$ spectrum of chesnatin, which will be reported in a subsequent paper, showed the presence of free and ester carbonyl carbons, a benzene ring having a symmetrical substitution pattern attributable to trihydroxybenzyl alcohol moiety, and glucose combined with $\beta$-linkage.

From these facts, chesnatin was considered to be mono ester of dehydrodigallic acid with crenatin. ${ }^{4}$ Thus the structure of chesnatin was considered as $\mathbf{I}$, although it remained to be established which carboxyl group of dehydrodigallic acid was esterified with crenatin. Chesnatin is a new compound which has never been previously encountered in nature.

\section{EXPERIMENTAL}

Unless otherwise noted, details for general procedures are described previously. ${ }^{2)}$

\section{Properties of chesnatin $(I)$}

Chesnatin (I) was obtained as colorless needles which showed no distinct melting point. Insoluble in hexane, benzene, chloroform, ether, ethyl acetate and anhydrous acetone, easily soluble in water and methanol. Reaction with $0.5 \%$ gelatin as well as with neutral lead acetate gave white precipitate, and the other tests for tannic substances were also all positive. It has a slightly bitter taste. Anal. Found: C, 50.00; H, 4.30. Calcd. for $\mathrm{C}_{27} \mathrm{H}_{28} \mathrm{O}_{18} \cdot 1 / 2 \mathrm{H}_{2} \mathrm{O}: C, 50.08 ; \mathrm{H}, 4.17 \% . \quad[\alpha]_{\mathrm{D}}^{20}$ $-7.3^{\circ}\left(c=1.16, \mathrm{H}_{2} \mathrm{O}\right) . \quad \mathrm{UV} \lambda_{\mathrm{max}}^{\mathrm{H}_{2} \mathrm{O}} \mathrm{nm}(\varepsilon): 271.5(16600)$, UV $\lambda_{\max }^{a 1 k a 11} \mathrm{~nm}: 289 . \quad I R \nu_{\max }^{\mathrm{KBr}} \mathrm{cm}^{-1}: 3440 \sim 3280,1680$, 1600, 1505, 1450, 1340, 1220, 1180, 1025, 910, 805, 770. $R f$ values on paper chromatogram: $0.45(2 \% \mathrm{AcOH})$, 0.42 (BAW).

\section{Acid hydrolysis}

Chesnatin $(21.424 \mathrm{mg})$, which was dried over phosphorus pentoxide at $90^{\circ} \mathrm{C}$ for $2.5 \mathrm{hr}$ in vacuo, was hydrolyzed with $0.5 \mathrm{~N}$ sulfuric acid $(1 \mathrm{ml})$ in a sealed tube on a boiling water bath for $50 \mathrm{~min}$. The reaction mixture was worked up according to the procedure mentioned previously.2) The results were given in Table I.

\section{Methylation}

Permethylation of chesnatin was performed by the method of Hakomori. ${ }^{5)}$ Chesnatin (29 mg), which was dried overnight at $60^{\circ} \mathrm{C}$ in vacuo over phosphorus pentoxide, was dissolved in dimethylsulfoxide $(2 \mathrm{ml})$ and treated with methyl sulfinyl carbanion solution which had been prepared by dissolving sodium hydride $(63 \mathrm{mg})$ in dimethylsulfoxide $(2 \mathrm{ml})$. The reaction mixture was stirred under nitrogen stream at room temperature for $20 \mathrm{~min}$, then methyl iodide $(0.2 \mathrm{ml})$ was added to the mixture little by little keeping the temperature below $20^{\circ} \mathrm{C}$ by cooling, and further stirred for $20 \mathrm{~min}$. The reaction mixture was diluted with chloroform $(10 \mathrm{ml})$ and the solution was washed with water. The chloroform layer was dried over anhydrous sodium sulfate and concentrated to syrup in vacuo. For the purification the syrup was applied to preparative TLC (Wakogel $\mathrm{B}-5 \mathrm{~F}$ ) using a mixture of benzene-methanol $(10: 1, \mathrm{v} / \mathrm{v})$. The methylated product separated into three bands $\mathrm{A}, \mathrm{B}$ and $\mathrm{C}$. The bands $\mathrm{A}(R f 0.87)$ and $\mathrm{C}(R f 0.37)$ were estimated to be pentamethyl-dehydrodigallic acid dimethyl ester and methyl tetra-O-methyl glucoside, respectively, on the basis of $R f$ values, fluorescence under UV light and color reaction sprayed with $40 \%$ sulfuric acid. The materials corresponding to band $\mathrm{B}(R f 0.73)$ were eluted with methanol and applied to preparative TLC once more using a mixed solvent of isopropyl ether-ethyl acetatemethanol $(20: 10: 1, \mathrm{v} / \mathrm{v})$. The band $(R f 0.36)$ corresponding to the desired material (III) was scrapped off, eluted with methanol and the eluate was concentrated to a small amount of viscous syrup. MS m/e: $806\left(\mathrm{M}^{+}, \mathrm{vw}\right), 755(\mathrm{vw}), 718(\mathrm{vw}), 702(\mathrm{vw}), 657(\mathrm{vw})$, 
$654(\mathrm{vw}), 640(\mathrm{w}), 602 \cdot(\mathrm{w}), 588(\mathrm{~m}), 572(\mathrm{vw}), 558(\mathrm{w})$, $436(\mathrm{~m}), 422(\mathrm{~s}), 405(\mathrm{w}), 373(\mathrm{~m}), 321(\mathrm{w}), 297(\mathrm{w}), 283$ (w), 267 (w), 255 (m), 248 (m), 241 (s), 223 (m), 219 (vs), 218 (es), 212 (vs), 198 (es), 195 (s), 187 (es), 181 (s), 167 (s), 159 (s), 155 (vs), 145 (s), 143 (s), 141 (s), 129 (s), 127 (vs), 116 (s), 111 (es), 101 (es). Abbreviations in the parentheses indicate the intensity; vw: very weak, $\mathrm{w}$ : weak, $\mathrm{m}$ : medium, s: strong, vs: very strong, es: extremely strong.

\section{Acetylation}

Solution of chesnatin (48 mg) in $2 \mathrm{ml}$ of acetic anhydride and $0.3 \mathrm{ml}$ of pyridine was allowed to stand overnight at room temperature. The mixture was poured into $50 \mathrm{ml}$ of ice-water and the resulted white precipitates (II) were collected by filtration. Yield $70 \mathrm{mg}$, mp $128 \sim 130^{\circ} \mathrm{C}$. Anal. Found: C, 53.50; H, 4.35. Calcd. for $\mathrm{C}_{48} \mathrm{H}_{48} \mathrm{O}_{28}: C, 53.45 ; \mathrm{H}, 4.36 \%$. $[\alpha]_{\mathrm{b}}^{23}+8.4^{\circ}\left(c=1.31, \mathrm{CHCl}_{3}\right)$. IR $\nu_{\max }^{\mathrm{KBr}} \mathrm{cm}^{-1}: 2950$, $1770,1750,1590,1490,1420,1365,1320,1180,1045$, 955, 885, 845, 815, 765. PMR $\delta_{\mathrm{TMS}}^{\mathrm{CDCl} 3} \mathrm{ppm}: 2.01,2.04$, $2.08,2.13\left(12 \mathrm{H}, \mathrm{s}\right.$, sugar $\left.4 \times \mathrm{OCOCH}_{3}\right), 2.27,2.29$, $2.31\left(21 \mathrm{H}, \mathrm{s}\right.$, aromatic $\left.7 \times \mathrm{OCOCH}_{3}\right), 3.65(1 \mathrm{H}, \mathrm{m}$, sugar proton), $3.91(1 \mathrm{H}, \mathrm{d}, J=12 \mathrm{~Hz}$, sugar proton), $4.37(1 \mathrm{H}$, dd, $J=12$ and $4 \mathrm{~Hz}$, sugar proton), $4.90(1 \mathrm{H}$, $\mathrm{m}$, sugar proton), $5.12 \sim 5.21(5 \mathrm{H}, \mathrm{m}$, three sugar protons and $\left.-\mathrm{CH}_{2}-\right), 6.89(2 \mathrm{H}, \mathrm{s}, \mathrm{Ar}-\mathrm{H}), 7.07(1 \mathrm{H}, \mathrm{d}$, $J=2 \mathrm{~Hz}, \mathrm{Ar}-\mathrm{H}), 7.62(1 \mathrm{H}, \mathrm{d}, J=2 \mathrm{~Hz}, \mathrm{Ar}-\mathrm{H}), 7.86$ (1H, s, Ar-H). MS m/e: 582 (vw), 570 (vw), 553 (vw), $540(\mathrm{vw}), 528(\mathrm{vw}), 510(\mathrm{vw}), 497(\mathrm{vw}), 486(\mathrm{vw}), 468$ (vw), $460(\mathrm{vw}), 444(\mathrm{w}), 426(\mathrm{vw}), 418(\mathrm{w}), 404(\mathrm{w})$, $402(w), 390(w), 384(v w), 376(w), 362(w), 360(\mathrm{~m})$, $348(\mathrm{~m}), 334(\mathrm{~m}), 331(\mathrm{~m}), 320(\mathrm{~m}), 318(\mathrm{~m}), 306(\mathrm{~m})$, $302(\mathrm{~m}), 292(\mathrm{~m}), 288(\mathrm{vs}), 276(\mathrm{~s}), 271(\mathrm{~m}), 248(\mathrm{w})$, $246(\mathrm{~s}), 240(\mathrm{~s}), 228(\mathrm{~s}), 223(\mathrm{~m}), 211(\mathrm{~m}), 198(\mathrm{~s}), 186$ (vs), 180 (vs), 169 (vs), 168 (vs), 157 (vs), 156 (vs), 155 (vs), 152 (s), 145 (vs), 144 (vs), 139 (vs), 138 (vs), 126 (es), 115 (vs), 113 (es), 109 (es), 98 (es). Rf value on TLC: 0.43 (Bz-MeOH, 5: 1).

\section{REFERENCES}

1) T. Ozawa, K. Haga, D. Kobayashi, T. Kamiyama and Y. Takino, Agric. Biol. Chem., 41, 1249 (1977).

2) T. Ozawa, K. Haga, N. Arai and Y. Takino, ibid., 42, 1511 (1978).

3) N. K. Kochetkov, N. S. Wulfson, O. S. Chizkov and B. M. Zolotarev, Tetrahedron, 19, 2209 (1963).

4) T. Ozawa, D. Kobayashi and Y. Takino, Agric. Biol. Chem., 41, 1257 (1977).

5) S. Hakomori, J. Biochem., 55, 205 (1964). 